\title{
PERANCANGAN APLIKASI MONITORING PRODUKSI PADA PERUSAHAAN YANG MEMPRODUKSI ACRYLIC
}

\author{
Nilo Legowo; I Made Kresna Yoga \\ Computer Science Department, School of Computer Science, Binus University \\ Jln. K. H. Syahdan No. 9 Palmerah Jakarta Barat 11480 \\ nlegowo@binus.edu
}

\begin{abstract}
A lot of problems often occur in production monitoring, because companies still rely on manual processing system. Therefore, this research is objected to facilitate the monitoring of production processes, to minimize human error in the production process, to make automatic the process of existing transactions, to clarify the duties of production monitoring of an acrylic manufacturer. The research methodology used is literature study by reviewing previous theories and studies related to the topic. Furthermore, analysis method by studying the running system of the company as well as evaluating the distributed questionnaire and analyzing the results. And finally is the design method using the Object-Oriented with UML. The research resulted in an application design of a production monitoring system. The result of this design has been implemented into the selected DBMS. The new monitoring system helps monitoring the production system properly, as well as makes the transaction run systematically. The each production process starting from project orders, sample orders, sales orders, material releases, production, assembly, and delivery order within can be monitored quickly and properly. The activity reports can also be generated more systematically and comprehensibly.
\end{abstract}

Keywords: analysis, design, monitoring system, production process

\begin{abstract}
ABSTRAK
Sistem pengolahan data secara manual sering kali mengakibatkan banyak masalah dalam proses monitoring produksi. Oleh karena itu, penelitian ini bertujuan untuk mempermudah monitor proses produksi, meminimalisasi human error pada proses produksi, mengotomatisasi proses transaksi yang ada, memperjelas pembagian tugas pada monitoring produksi acrylic pada perusahaan. Metodologi penelitian yang digunakan adalah studi kepustakaan, yaitu dengan mengkaji teori dan tulisan sebelumnya yang berhubungan dengan topik penelitian. Kemudian metode analisis dengan mempelajari sistem yang sedang berjalan pada perusahaan serta menganalisis hasil kuesioner yang telah disebarkan. Terakhir adalah metode perancangan yaitu dengan pendekatan Object-Oriented menggunakan berbagai macam diagram yang ada di model UML. Penelitian ini telah menghasilkan rancangan aplikasi sistem monitoring produksi. Hasil rancangan ini untuk implementasi dengan memakai DBMS yang telah dipilih. Dengan sistem monitoring produksi yang dirancang untuk perusahaan ini, proses transaksi dapat berjalan secara sistematis. Selain itu, setiap proses produksi mulai dari project order, sample order, sales order, material release, production, assembly, dan delivery order dapat dipantau dengan cepat sehingga laporan kegiatan proses produksi dapat dibuat lebih sistematis dan jelas.
\end{abstract}

Kata kunci: analisis, perancangan, sistem monitoring, proses produksi 


\section{PENDAHULUAN}

Sering kali kita melihat bahwa banyak terjadi masalah dalam hal proses produksi yang dimulai dari penyiapan data, bagaimana mengolah data seperti project order, sample order, sales order, material release, production, assembly, dan delivery order yang masih mengandalkan sistem pengolahan data manual. Sistem ini menyebabkan kesulitan dalam membuat laporan-laporan di kemudian harinya.

Masalah yang terjadi dalam suatu perusahaan dapat diselesaikan dengan pengelolaan data dan juga dukungan dari teknologi informasi yang baik . Dengan teknologi ini dapat membantu transaksi suatu perusahaan sehingga dapat memudahkan setiap transaksi dan semua pekerjaan yang akan dilaksanakan. Oleh sebab itu, berbagai perusahaan berusaha terus menerus mengembangkan setiap teknologi mereka untuk meningkatkan produktivitas dan kinerja dari perusahaan itu sendiri.

Survei yang lakukan di perusahaan yang bergerak dalam bidang pembuatan, produksi, dan penjualan bermacam-macam produk dari akrilik menjadi dasar dari penulisan penelitian ini. Penelitian ini memiliki tujuan sebagai berikut: (1) mempermudah memonitor proses produksi, perakitan komponen produk yang terbuat dari bahan Acrylic; (2) meminimalisir human error pada proses produksi; (3) mengotomatisasi proses transaksi yang terjadi pada sistem monitoring produksi secara keseluruhan; (4) memperjelas pembagian tugas (segmentasi) pada sistem monitoring produksi.

Untuk pembahasan topik penelitian yang lebih terarah dan terfokus pada tujuan yang ingin dicapai, penelitian ini membahas hal-hal sebagai berikut: (1) perancangan database yang digunakan untuk menyimpan data yang berkaitan dengan sistem monitoring produksi; (2) sistem monitoring produksi akan dibahas dengan tahapan sebagai berikut: (a) proses pembuatan Project Order; (3) penelitian Raw Material (RM), proses produksi, cost, dan Person In Charge (PIC) di Sample Order (SAO) berdasarkan Project Order; (c) pembuatan Sales Order (SO) berdasarkan Sample Order (SAO) yang sudah di confirm; (d) jumlah dan penelitian Raw Material (RM) yang dibutuhkan untuk membuat Project Order yang sudah di-confirm di Sales Order (SO) akan dijabarkan pada material release (MR) yang ditujukan ke bagian gudang; (e) jumlah raw material (RM) yang sudah dikeluarkan oleh gudang akan melalui beberapa tahapan proses produksi berdasarkan proses yang sudah ditetapkan di Sample Order (SAO); (f) raw material (RM) yang sudah mencapai proses akhir dan siap dirakit akan dilanjutkan ke proses assembly; (g) setelah melewati assembly, barang yang sudah siap dikirim akan didata di Delivery Order (DO) sebelum melakukan pengiriman; (4) data meliputi baik yang sudah terdapat pada perusahaan maupun yang nantinya akan dimasukkan, dimana data tersebut hanya dapat diubah oleh user yang diberikan otoritas.

\section{METODE}

Metode yang digunakan dalam penelitian ini terdiri dari metode studi kepustakaan, yaitu dengan mengkaji teori dan tulisan sebelumnya yang berhubungan dengan topik penelitian; metode analisis yaitu dengan melakukan penyebaran kuesioner dan mempelajari sistem yang sedang berjalan pada perusahaan serta menganalisis hasil kuesioner; metode perancangan yaitu dengan pendekatan Object-Oriented dengan menggunakan berbagai macam diagram yang ada di model UML.

Studi kepustakaan dilakukan dengan cara mempelajari buku-buku yang berhubungan dengan objek penulisan sebagai dasar teori dalam penyusunan penelitian ini. 
Analisis dengan survey untuk mempelajari sistem yang ada, pengumpulan data dan analisis data perusahaan dan membuat merancang aplikasi untuk sistem monitoring produksi pada Perusahaan.

Metode Analisis dilakukan melalui tiga tahapan yaitu: (1) menggunakan beberapa pertanyaan mengenai system yang ada dan program yang akan di rancang pada pihak yang bersangkutan melalui kuesioner; (2) mempelajari sistem yang sedang berjalan pada perusahaan; (3) analisis terhadap hasil kuesioner.

Dalam penelitian ini metode perancangan sistem yang digunakan adalah Object Oriented Analysis Design (OOAD) melalui pendekatan Unified ModellingLanguage (UML).

\section{KajianTeori}

Sistem Basis Data Menurut Connolly \& Begg (2010, p.14) adalah sekumpulan data yang secara logika saling berkaitan dan gambaran dari data ini dirancang untuk mendapatkan informasi yang dibutuhkan oleh suatu organisasi.

Menurut Connolly \& Begg (2010, p16-20), DBMS adalah sebuah sistem software yang memungkinkan user untuk mendefinisikan, membuat, me-maintain dan mengontrol akses ke basis data. people.

Ada beberapa komponen DBMS, di antaranya: hardware, software, data, procedure, dan

Unified Modelling Languange (UML) menurut Booch, Jacobson dan Rumbaugh adalah metode generasi ketiga untuk menspesifikasikan, memvisualisasikan dan mendokumentasikan suatu pengembangan sistem yang berorientasi objek.

Menurut Whitten et al (2004, p.271), use case diagram adalah diagram yang menggambarkan interaksi antara sistem, eksternal sistem dan user. Dengan kata lain, diagram ini menjelaskan siapa yang akan menggunakan sistem tersebut dan bagaimana cara user tersebut berinteraksi dengan sistem.

Selanjutnya, Whitten et al. (2004, p441) mendefinisikan Class diagram sebagai gambaran struktur objek yang terdapat pada sebuah sistem. Diagram ini menunjukkan objek-objek yang terdapat pada suatu sistem serta relasi antar objek-objek tersebut.

Whitten et al. (2004, p442) juga mendefinisikan sequence diagram sebagai gambaran bagaimana objek berinteraksi antara satu dengan yang lain melalui message dalam eksekusi dari sebuah use case atau sebuah operasi.

Interaksi manusia dan komputer (IMK) merupakan disiplin ilmu yang berhubungan dengan perancangan, evaluasi, dan implementasi sistem komputer interaktif untuk digunakan oleh manusia, serta studi fenomena-fenomena besar berhubungan dengannya.

Delapan aturan emas adalah prinsip-prinsip mendasar untuk desain antarmuka. Peraturan ini diperoleh berdasarkan pengalaman pembuatan desain. Berikut ini adalah Delapan Aturan Emas tersebut (Shneiderman, 2010, p.75): (1) berusaha untuk konsisten; (2) memenuhi kegunaan yang universal; (3) umpan balik yang infomatif; (4) membuat dialog untuk menghasilkan keadaan akhir; (5) memberikan penanganan kesalahan yang sederhana; (6) mengizinkan pembalikan aksi; (7) mendukung pusat kendali internal; (8) mengurangi beban ingatan jangka pendek. 
Di dalam suatu produksi ada hal-hal yang harus diperhatikan (Nasution, 2003, p.18 ), di antaranya: komposisi input yang bagaimana yang harus digunakan, bagaimana proses produksi berlangsung agar tingkat produksi maksimal, komposisi input yang bagaimana yang harus digunakan, dan bagaimana proses produksi dilaksanakan agar biaya produksi serendah mungkin?

Yang dimaksud dengan teori produksi adalah teori yang menjelaskan hubungan antara tingkat produksi dengan jumlah faktor-faktor produksi dan hasil penjualan output-nya. Di dalam menganalisis teori produksi, kita mengenal dua hal: produksi jangka pendek dan produksi jangka panjang

\section{HASIL DAN PEMBAHASAN}

Penelitian ini menggunakan metode analisis dan perancangan system aplikasi dan dalam pengembangannya menggunakan pendekatan object-oriented dengan membuat diagram-diagram untuk menggambarkan disain dan flow system, untuk mempermudah dalam proses pembuatan program yang dimulai dari membuat perancangan database, yang dalam pembahasan ini ditampilkan beberapa hasil rancangan Class diagram yang meliputi: Class diagram untuk Sales Order, untuk Produksi dan Class diagram untuk Delivery Order seperti yang dijelaskan pada Gambar 1, 2 dan 3.

\section{Spesifikasi Perangkat Keras dan Perangkat Lunak}

Pada tahap ini akan disiapkan perangkat lunak dan perangkat keras yang dibutuhkan untuk penerapan sistem monitoring produksi. Spesifikasi perangkat lunak dan perangkat keras yang diusulkan adalah seperti berikut:

\section{Perangkat Keras}

Server:Processor Intel Xeon E5335, Memory 1 Gbyte FDDR2 - 677EEC, Harddisk 250GB HDD SATA, Network Card GbE NIC, Graphic VGA ATI 16 MB, Monitor LG LCD 19", Keyboard dan Optical Mouse Logitech, Switch 16 - Ports 10/100/1000 L2 + 4- Ports Gigabit SFP , Printer C2HP Deskjet 3320.

Client: Processor Pentium IV 2,4 GHz, Memory DDR2 - 800Mhz 512 MB, Harddisk 80GB HDD SATA, Network Card 10/100 MbE NIC, Graphic VGA Intel GMA 3000, Monitor LG LCD 17”, Keyboard dan Optical Mouse Logitech, Printer Epson LX-800.

\section{Perangkat Lunak:}

Server: Sistem Operasi Microsoft Windows, Server 2003 RC2 SP2, Database Management Systems, Microsoft SQL Server 2000 Enterprise Edition.

Client: Sistem operasi Microsoft Windows XP Professional SP2, aplikasi .NET Framework 3.5 Microsoft SQL Server Client Compacts 3.5, Crystal Reports Basic for Visual Studio 2008, Visual $\mathrm{C}++$ Runtime Libraries (x86).

\section{Hasil Tampilan Layar}

Berikut ini adalah langkah-langkah cara pengoperasian pada sistem monitoring produksi yang telah dirancang: setelah membuka program ini dari shortcut yang ada di menu, akan muncul tampilan awal dari aplikasi sistem monitoring produksi, selanjutnya user diminta login dengan mengisi menu login yang ada dalam tampilan layar login pada aplikasi. Silahkan memasukkan User ID dan Password anda dengan benar. Bila ada kesalahan saat memasukkan User ID maupun Password, sistem akan menampilkan pesan kesalahan sesuai dengan kesalahan yang dilakukan oleh user. Jika User ID 
dan password yang dimasukkan benar, aplikasi akan menampilkan menu utama seperti terlihat pada Gambar 4 yaitu menu master, transaction, master report, dan transaction report.

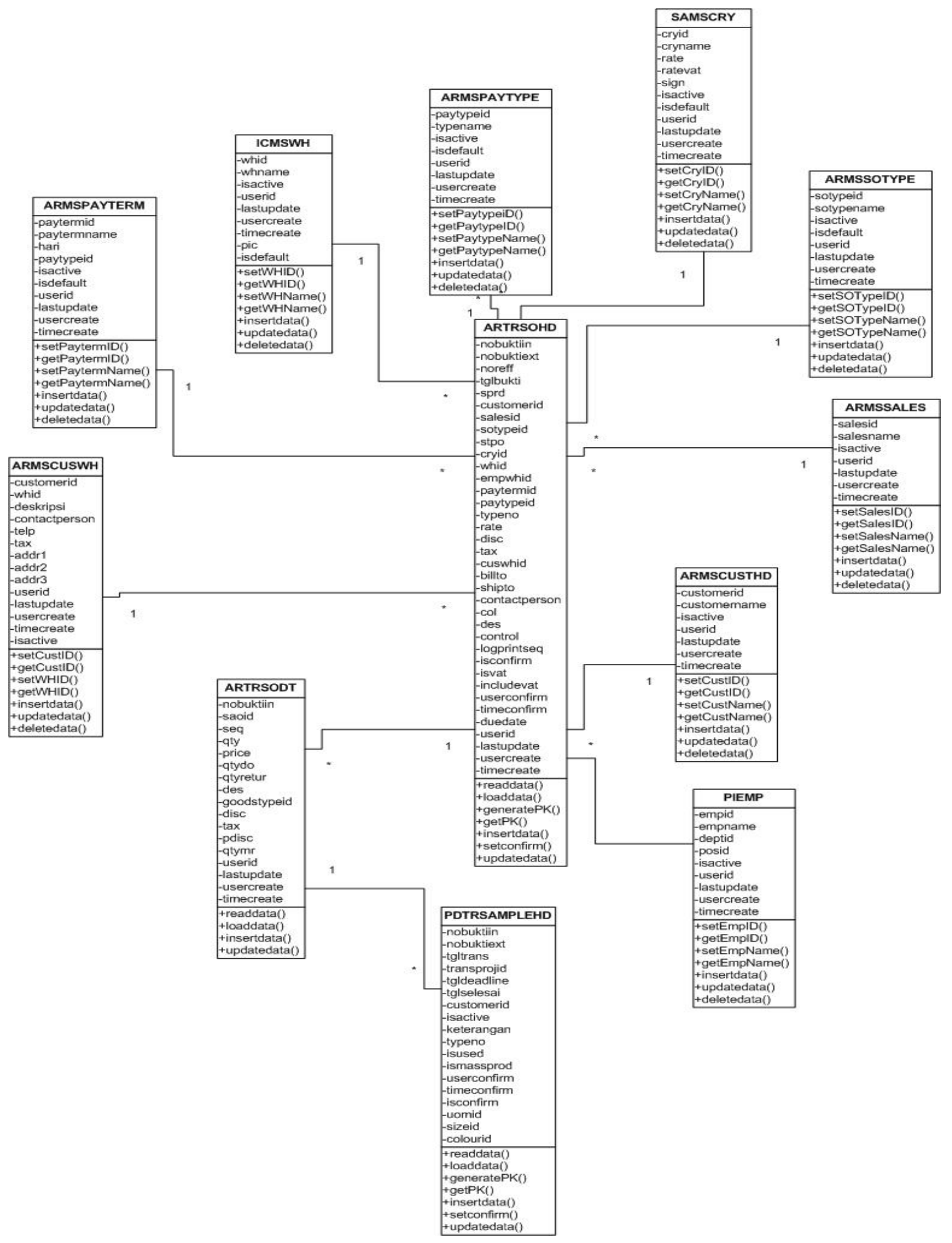

Gambar 1. Class Diagram untuk Sales Order. 


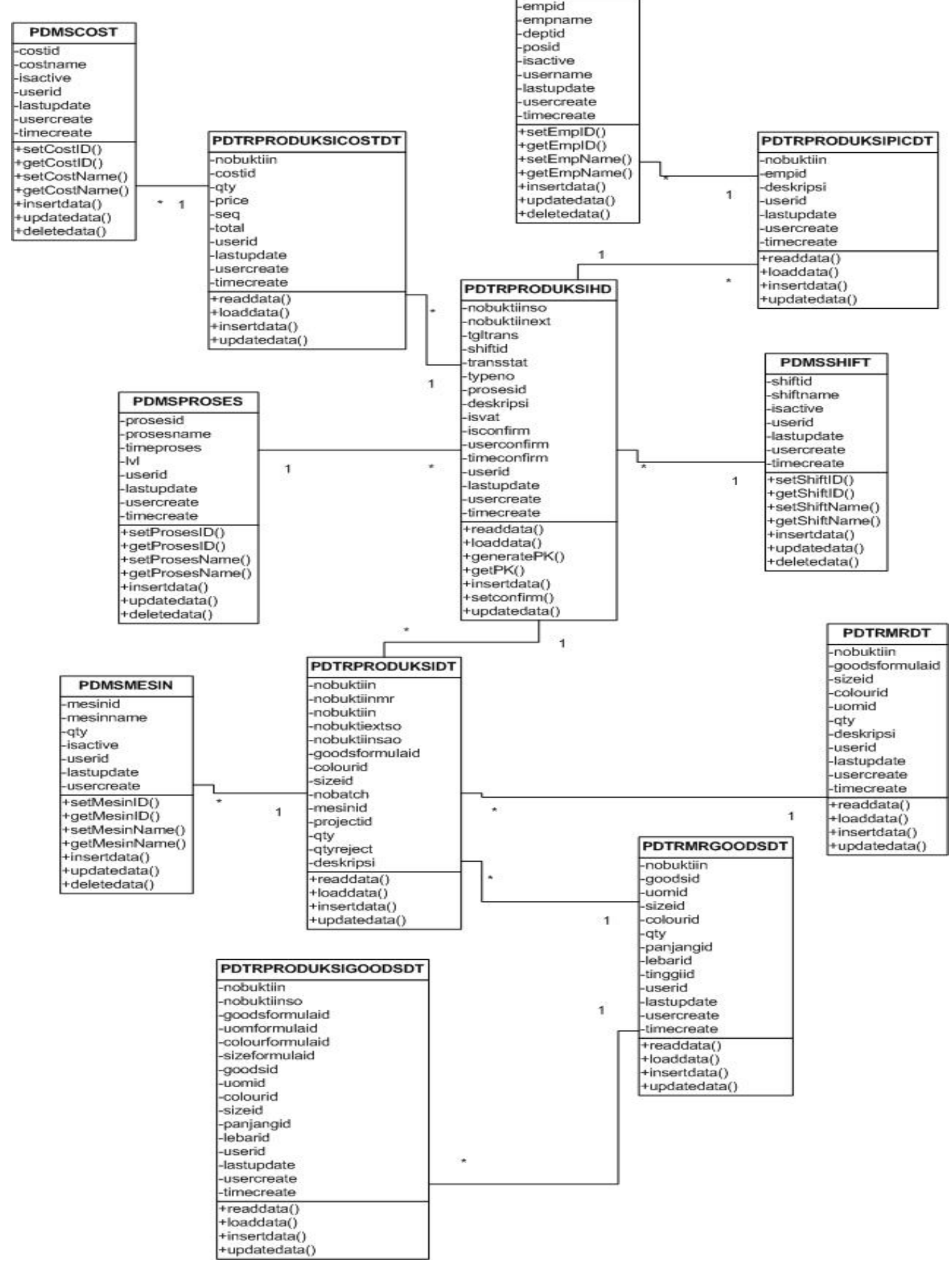

Gambar 2. Class diagram untuk produksi. 


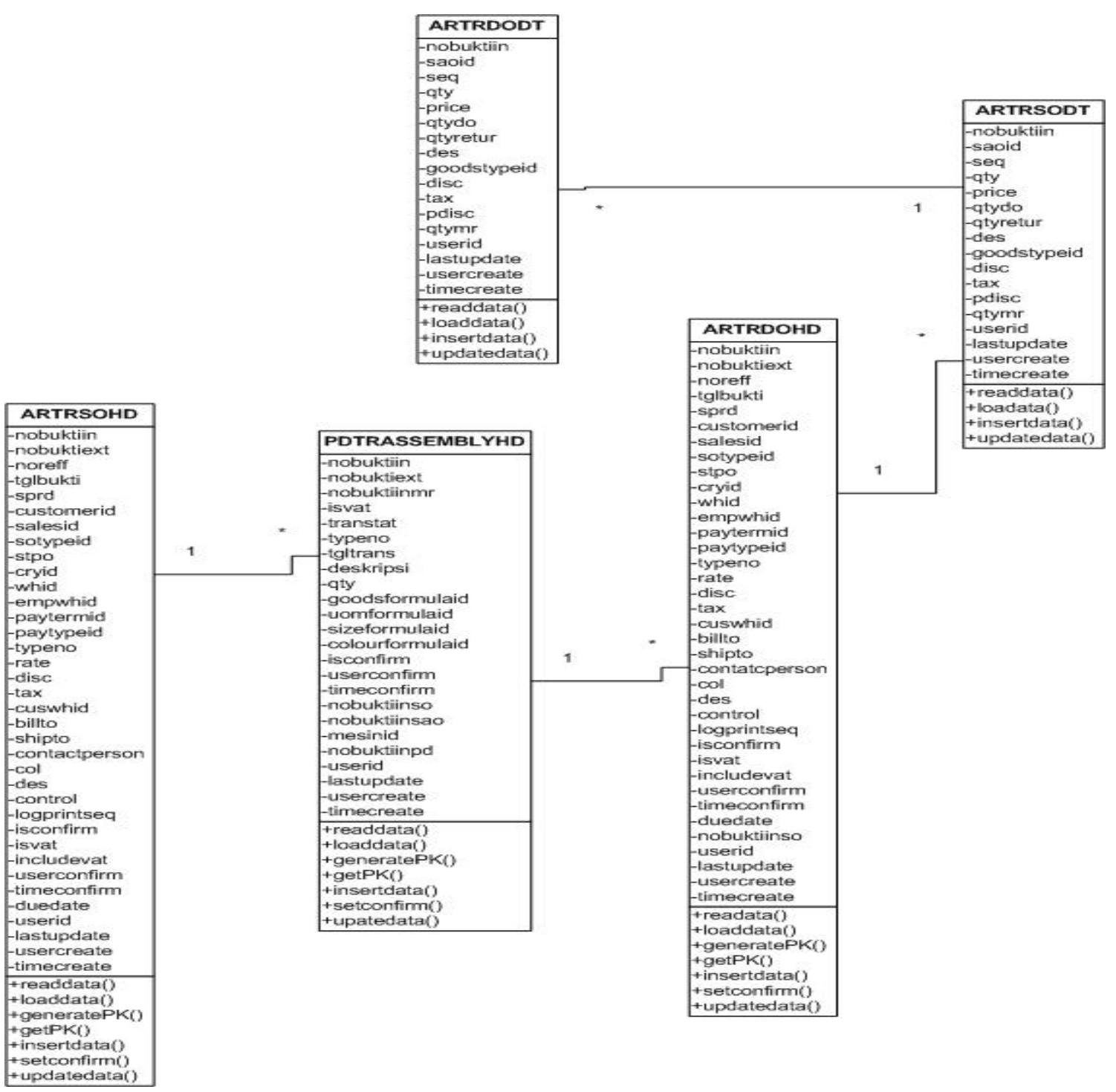

Gambar 3. Class diagram untuk Delivery Order.

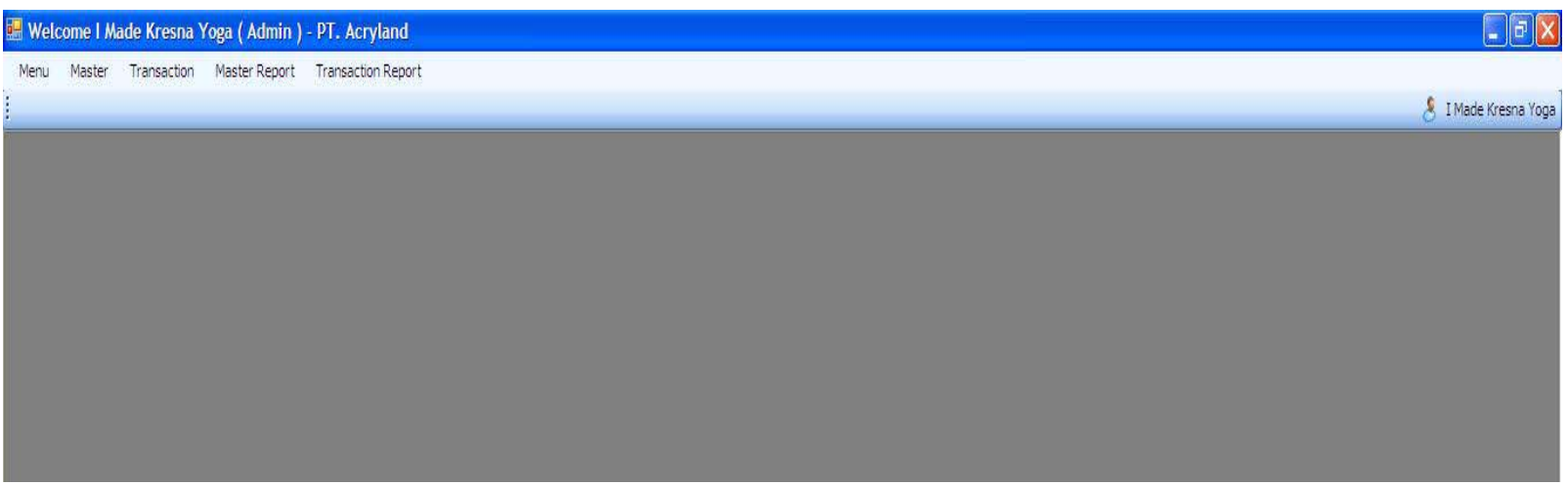

Gambar 4. Tampilan layar Menu Utama. 
Jika anda ingin melihat data customer yang telah disimpan, anda dapat memilih Master , lalu pilih Account Receivable lalu pilih Customer seperti terlihat pada Gambar 5. Jika anda ingin menambahkan data customer, anda dapat mengklik tombol Insert. Bila anda ingin mengupdate dari data customer yang sudah ada maka anda dapat mengklik tombol Update.

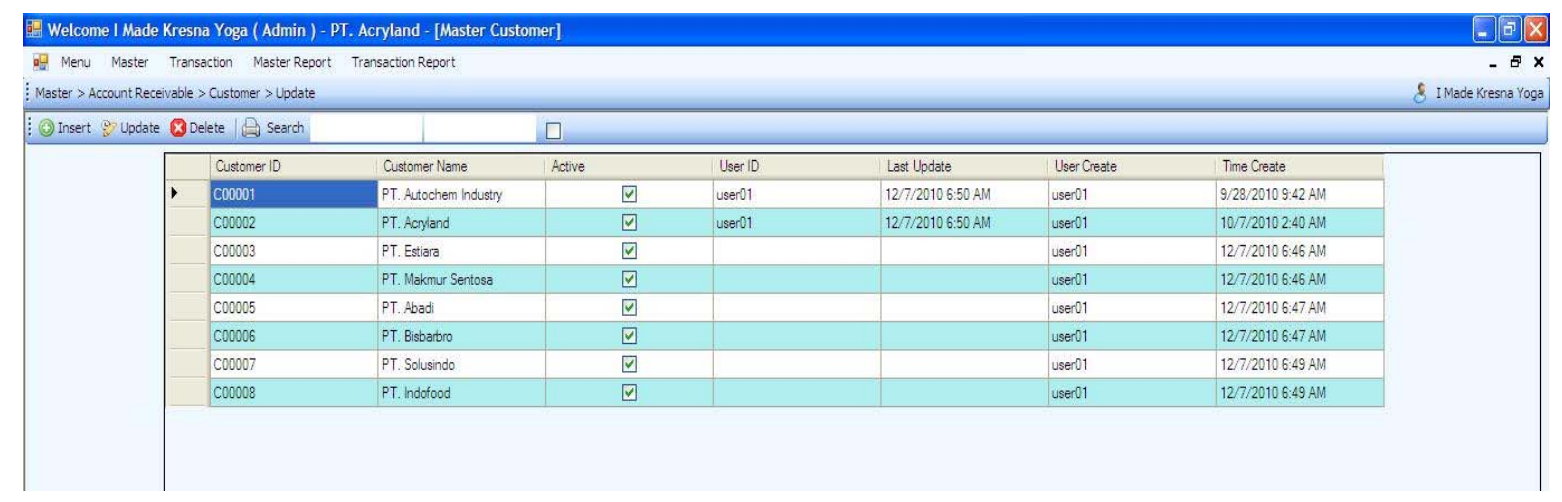

Gambar 5. Tampilan Layar Master Customer.

Pada tampilan layar Transaction Project (Gambar 6) user dapat membuat project baru. Kita dapat mengaksesnya dengan mengklik Transaction pada menu, pilih Production, lalu pilih Project. Lalu kita dapat mengkonfirmasi dengan tombol confirm dan bisa membatalkannya dengan tombol unconfirm. Kita juga dapat melihat history dengan tombol View History.

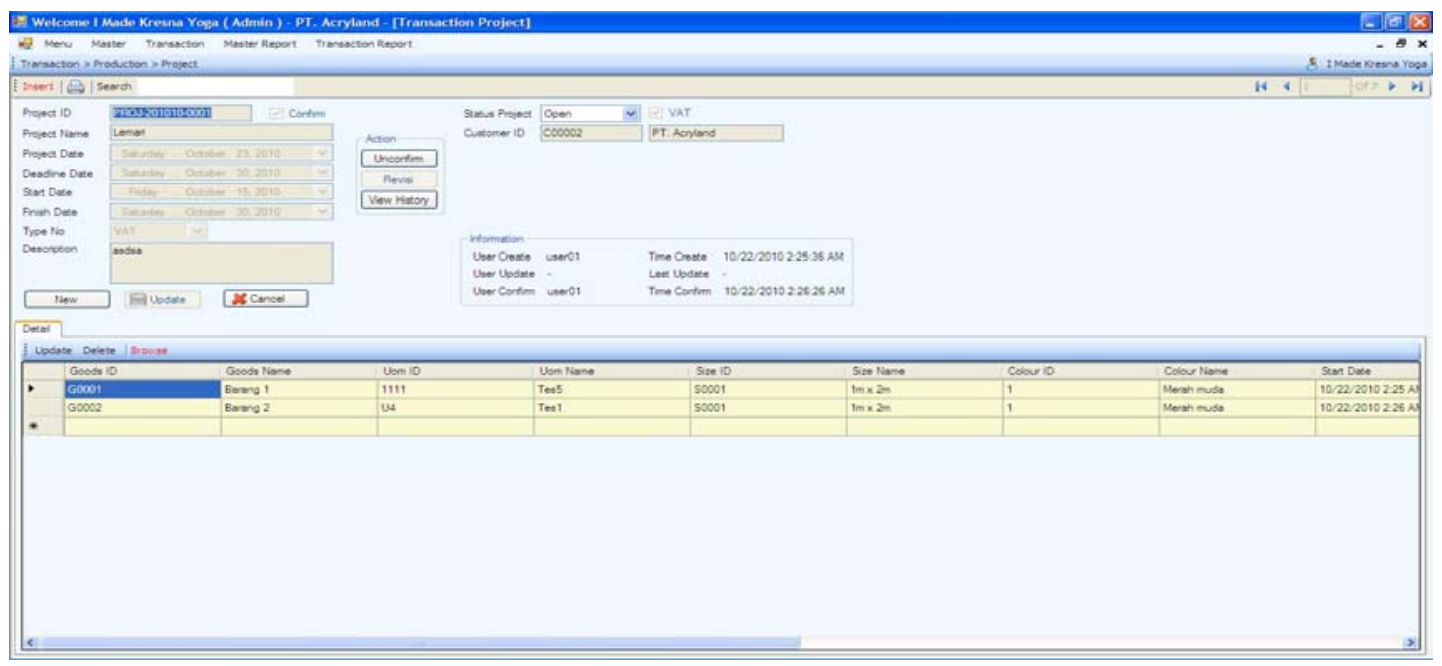

Gambar 6. Tampilan Layar Transaction Project.

Tampilan layar LookUp Transaction Project (Gambar 7), digunakan untuk memudahkan mengisi data-data yang ada dalam field dengan cara menekan F2 sehingga cepat dimasukkan. Data didapat dari data yang telah di-input di dalam master. 


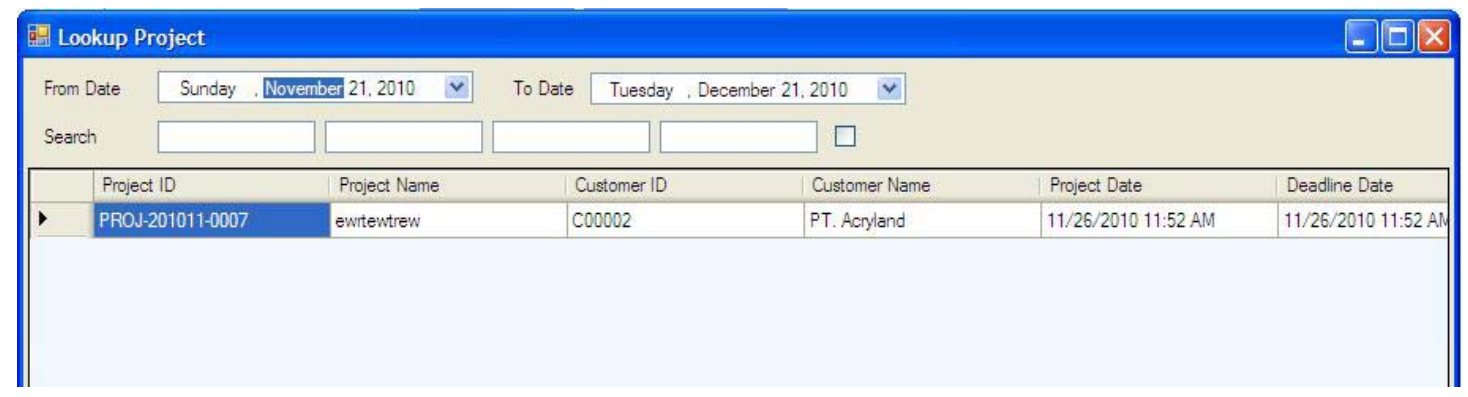

Gambar 7.Tampilan Layar LookUp Transaction Project.

Gambar 8 di bawah ini merupakan tampilan layar Report Master Customer. Di halaman ini kita dapat melihat data semua customer dengan melihat report sesuai data yang dimasukkan pada master. Untuk melihat report dengan cara klik Master Report lalu Account Receivable lalu Customer. Kita dapat memilih data yang dapat kita tampilkan dengan memilih pada look up report customer.

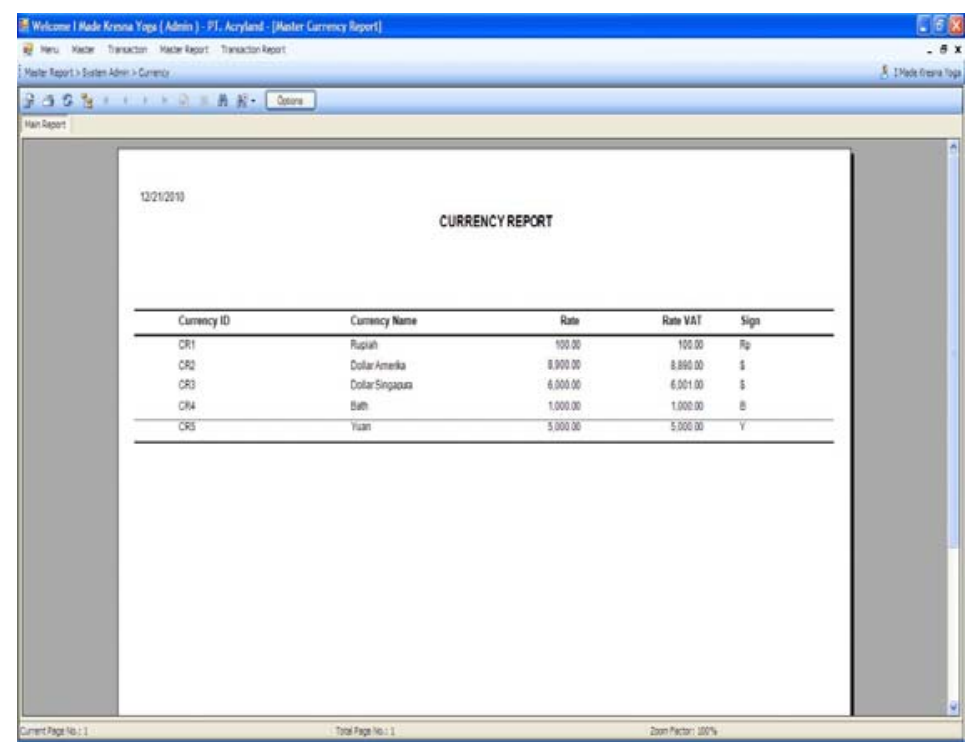

Gambar 8. Tampilan layar Master Report.

Pada Gambar 9 kita dapat melihat tampilan layar Report Master Customer. Di halaman ini kita dapat melihat data semua customer dengan melihat report sesuai data yang dimasukkan pada master. Untuk melihat report dengan cara klik Master Report lalu Account Receivable lalu Customer. Kita dapat memilih data yang dapat kita tampilkan dengan memilih pada look up report customer.

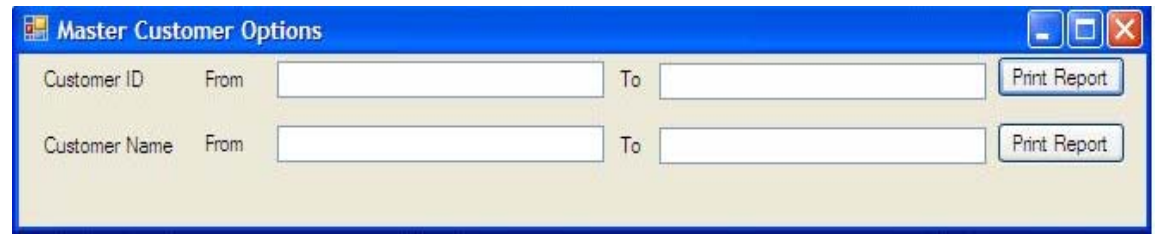

Gambar 9. Tampilan Layar Look Up Master Report Customer. 


\section{PENUTUP}

Berdasarkan hasil analisis dan perancangan system aplikasi Monitoring Produksi yang telah dilakukan pada perusahaan, kesimpulan yang dapat diambil adalah: (1) adanya aplikasi sistem monitoring produksi dapat mempermudah dan mempercepat dalam memonitor proses produksi yang sedang berlangsung karena menyediakan fungsi untuk membuat report produksi dan report-report lainnya yang mendukung proses produksi barang mulai dari awal pemesanan (project order) hingga pengiriman (delivery order),juga penyajian data menjadi lebih terintegrasi dibandingkan dengan sistem manual; (2) sistem dapat membantu tugas user berdasarkan bagiannnya misal bagian marketing mengelola modul project order dan sample order, bagian sales mengelola modul sales order dan delivery order, warehouse pic mengelola material release, dan bagian produksi mengelola produksi dan assembly; (3) sistem mengkoordinasikan setiap modul sistem sehingga saling terkait satu sama lain yang dapat mempermudah dan mempercepat komunikasi antar bagian dan dapat mengetahui laporan produksi dalam satu project dengan cepat; (4) sengan sistem aplikasi monitoring produksi ini keamanan data perusahaan lebih terjamin.; (5) dengan User Interface yang menarik dan fungsi otomatisasi yang disediakan oleh sistem dapat meningkatkan kinerja karyawan.

Saran yang dapat penulis berikan untuk pengembangan selanjutnya adalah sebaiknya aplikasi yang dibuat dapat diintegrasikan dengan sistem akuntansi untuk memperkirakan kebutuhan biaya produksi.

\section{DAFTAR PUSTAKA}

Connolly, Thomas \& Begg, Carolyn. (2010). Database Systems: A Practical Approach to Design, Implementation, and Management (5th edition). New Jersey: Addison-Wesley.

Nasution, Arman Hakim. (2003). Perencanaan dan Pengendalian Produksi. Surabaya: Guna Widya.

Whitten, Jeffrey L., Bentley, Lonnie D. \& Dittman, Kevin C. (2004). Systems Analysis and Design Methods ( $3^{\text {rd }}$ edition). New York: McGraw-Hill. 